\title{
Duty to Publish
}

\author{
Cynthia Jackevicius
}

A s I read through the list of Canadian Society of Hospital Pharmacists award winners recently, I was impressed by the range of projects targeting appropriate medication use! I thought, "I hope they are published". It occurred to me shortly thereafter that I was accepting the possibility that someone who had spent a couple years on a project would complete it and receive an award, yet not disseminate the results as expected, through publication. While this may seem strange, I'm sure we can all relate and might even assume it normal to not always end up publishing our research. Raise your hand if you have had a research study or project that has been stuck at the abstract stage for far longer than it deserves. If you raised your hand, you, like me, are a typical mortal who does not always have writing superpowers and has simply hit the stage of manuscript inertia.

Just recently, I was mentoring a colleague in crafting a message for his great study that has been waiting in the manuscript line for a bit too long. I encouraged him not to give up at the final mile of the research marathon, as I could tell his energy for the project was lagging. Manuscript inertia doesn't always occur. Sometimes, the results are so exciting that we are eager to publish right away! Sometimes, our promotion or performance review depends on publication, and the motivation is easy. Sometimes, our own pride in our work brings us over the finish line. But given that almost $50 \%$ of abstracts presented at scientific meetings never make it to manuscript publication, I think we have a lot of company. ${ }^{1}$ Why does manuscript inertia happen, and how can we bring our projects to the finish line?

Is it because we took a science-based curriculum, and have not been trained to write? Possibly, although guides on scientific writing are certainly available., ${ }^{2,3}$ know it took me a while to develop my own writing skills, and I benefited from many writing mentors along the way. Perhaps those who write well don't realize how important their mentorship would be to novice writers. But it also takes time, trial and error, and persistence. It has been said that if you want to write well, write something daily and it will make a difference, since writing is a skill that takes practice.

\begin{abstract}
With writing, I have found that starting is often the hardest part. So how do we tackle this? Some of the roadblock comes down to prioritizing and simply making it happen. Easier said than done? We are all overscheduled, and prioritizing may be difficult. I still find the seemingly simple,
\end{abstract} yet sage advice from

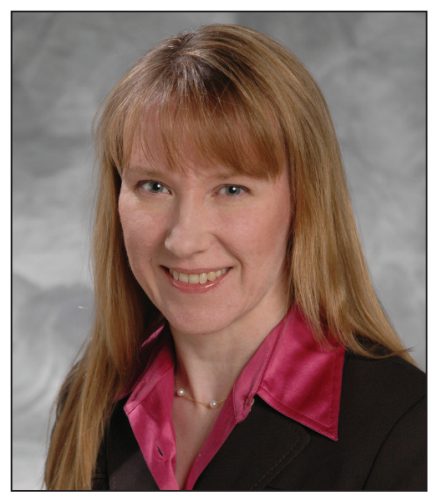
Stephen Covey, in his famous book The 7 Habits of Highly Effective People, ${ }^{4}$ helpful. He suggests just a slight change in mindset: "The key is not to prioritize what's on your schedule, but to schedule your priorities." Covey recommends putting our activities into 4 quadrants based on importance and urgency, and I find this an effective mental framework. For me, as for many, it is the Quadrant 1 activities, which are important and urgent (crises, pressing problems), that often get done. But Quadrant 2 activities, which are important but not urgent (like writing papers with no firm deadlines), are what often fall by the wayside, since Quadrant 3 activities, which are (or appear to be) urgent but aren't actually important (interruptions, many emails and meetings), seem to cut into our precious time. Even worse, Quadrant 4 activities, which are neither urgent nor important (Mindless binge-watching of Netflix anyone? Or mindless checking of social media, "busy" work?), are the real time-sucking vampires. When I remember to prioritize Quadrant 2 activities, especially during the times of the day when I am most focused, I am able to get more important work, like writing manuscripts, back on track.

When we require even more motivation to quell our inertia, the short, humorous book Eat That Frog! by Brian Tracy provides eye-opening insights. ${ }^{5}$ Mark Twain once said that if the first thing you do in the morning is to eat a frog, then you can go through the rest of the day knowing that this was probably the worst thing 
that was going to happen all day. According to Tracy, your "frog" is the biggest, most important activity that you need to do, but also the one you are most likely to procrastinate on. For us, the proverbial frog is the manuscript that is sitting there croaking at us, waiting for us to write.

Besides using these approaches to help create a slight but important shift in mindset, I have been reflecting on our real purpose in writing manuscripts. It may be obvious, but the ultimate goal of our research is to help patients. So how can we use this goal to help with publishing our research? Many pharmacists have no problem staying at work 10-15 minutes late to help individual patients, because we know we will do something to help improve their health. Their needs are palpable, and we can identify with them because we are in direct contact with them. Therefore, the reward of our efforts, along with an accompanying dopamine surge, is relatively immediate gratification. In contrast, the amorphous and ill-defined phrase "helping patients by publishing our research" may be a bit too intangible and remote to stimulate motivation for many people.

When publishing our research doesn't provide tangible rewards, like pride, recognition, or promotion, harnessing the same altruistic force that drives us to help our individual patients may carry us past manuscript inertia, that is, thinking about publication as an altruistic way to affect many patients and improve their outcomes. Perhaps some people recall this motivation easily, and quickly circle back to why they did their study in the first place. But often, after a couple years bogged down with all of the research project logistics, we may forget our original patient-centric motivations and need a reminder.

If we change our perspective and realize that we are going to help even just one patient—perhaps by visualizing a tangible image of an actual patient that we could be helping - by publishing our work, we can develop a clear sense of its importance. Then, I find we are able to prioritize extra minutes here and there to dedicate to the project and to the necessity of writing.

Besides altruism as our stimulus, I have also been pondering whether it may in fact be considered unethical for us to delay dissemination of our research. We often take the moral high ground and consider pharmaceutical companies that restrict or delay publication of completed trials as unethical. Perhaps we need to consider the ethics of "holding back our own research" in a similar vein.

I have proposed some concepts, from writing mentors and quadrants to frogs, altruism, and ethics, as potential tools for you as you battle manuscript inertia. I urge you not to think about publishing as something nice to do someday, but instead to commit to spending 15 minutes each day to start harnessing your Quadrant 2 activities, eating your frog, and considering your ethics. But above all, I ask you to consider the altruism of publishing research and how, in fact, it is our duty to publish to help improve patient care.

\section{References}

1. Scherer RW, Ugarte-Gil C, Schmucker C, Meerpohl JJ. Authors report lack of time as main reason for unpublished research presented at biomedical conferences: a systematic review. J Clin Epidemiol. 2015;68(7):803-10.

2. Edwards DJ. Dissemination of research results: on the path to practice change. Can J Hosp Pharm. 2015;68(6):465-9.

3. Wagner PD. Writing up your research results for publication. Chest. 2009; 136(2):639-42.

4. Covey SR. The 7 habits of highly effective people. New York (NY): Free Press; 1989.

5. Tracy B. Eat that frog! San Francisco (CA): Berrett-Koehler Publishers, Inc; 2007.

Cynthia Jackevicius, BScPhm, PharmD, MSc, is Professor with the Department of Pharmacy Practice, Western University of Health Sciences, Pomona, California, and Senior Adjunct Scientist with the Institute for Clinical Evaluative Sciences, Toronto, Ontario. She is also an Associate Editor with the Canadian Journal of Hospital Pharmacy.

Competing interests: None declared.

Address correspondence to:

Dr Cynthia Jackevicius

College of Pharmacy

Western University of Health Sciences

309 E Second Street

Pomona CA 909469-5527

e-mail: cjackevicius@westernu.edu 